\title{
Selective preparation of tetrasubstituted fluoroalkenes by fluorine-directed oxetane ring-opening reactions
}

\author{
Clément Q. Fontenelle, Thibault Thierry, Romain Laporte, Emmanuel Pfund \\ and Thierry Lequeux*
}

\author{
Full Research Paper \\ Address: \\ Normandie Université, Laboratoire de Chimie Moléculaire et \\ Thioorganique LCMT UMR 6507, ENSICAEN, UNICAEN, CNRS, \\ 6 Bd. du Maréchal Juin, 14050 Caen, France \\ Email: \\ Thierry Lequeux* - Thierry.Lequeux@ensicaen.fr \\ * Corresponding author \\ Keywords: \\ acyclonucleotide; fluorine; monofluoroalkene; oxetane; selective \\ ring-opening reaction; tetrasubstituted alkene
}

Open Access

\author{
Beilstein J. Org. Chem. 2020, 16, 1936-1946. \\ doi:10.3762/bjoc. 16.160 \\ Received: 27 May 2020 \\ Accepted: 23 July 2020 \\ Published: 07 August 2020 \\ This article is part of the thematic issue "Organo-fluorine chemistry V". \\ Guest Editor: D. O'Hagan \\ (C) 2020 Fontenelle et al.; licensee Beilstein-Institut. \\ License and terms: see end of document.
}

\begin{abstract}
The selective ring-opening reaction of fluoroalkylidene-oxetanes was directed by the presence of the fluorine atom, enabling a twostep access to tetrasubstituted fluoroalkenes with excellent geometry control. Despite its small van der Waals radii electronic, rather than steric influences of the fluorine atom governed the ring-opening reaction with bromide ions, even in the presence of bulky substituents.
\end{abstract}

\section{Introduction}

The introduction of fluorine atoms into organic compounds is known to modify their biological and physiological properties and can enhance the half-life of drugs in vivo [1-4]. During the last decade, fluorinated nucleoside analogues have received increasing interest, as is illustrated by the two pharmaceutical leads gemcitabine (I) and sofosbuvir (II), potent anticancer or antiviral agents, respectively (Figure 1) [5,6]. The field of acyclonucleotides (ACN) has been explored less, however, the introduction of fluorine atoms showed remarkable effects. The most representative examples are phosphate analogues such as the nucleoside phosphorylase inhibitor III and acyclic nucleotides such as the antiviral agent FPMPA (IV) [7-9].
Other main structural modifications of ACN relied on the introduction of a hydroxy group into the aliphatic chain to improve hydrogen bonding with enzymes [10], or of a carbon-carbon double bond to constrain the aliphatic chain and to limit conformational changes [11-13]. For the latter, nucleoside analogues (Figure 2, VI) containing a trans-butenyl moiety where the endocyclic $\mathrm{C}-\mathrm{O}$ bond was replaced by a $\mathrm{C}=\mathrm{C}$ bond are recognized by kinases as dUMP surrogate (V) [11]. However, there is no existing data for the corresponding fluoroalkene (VII), as the latter was not yet synthetized. It is expected that the introduction of fluorine into the carbon-carbon double bond, in a position equivalent to the ring oxygen of the naturally occurring 


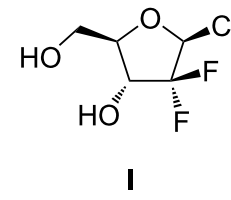

gemcitabine

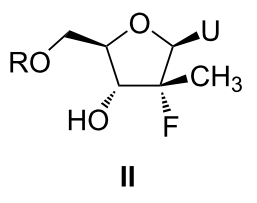

sofosbuvir

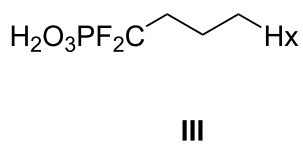

PNP inhibitor<smiles>CCC(CF)OCPO</smiles>

IV

FPMPA

Figure 1: Representative fluorinated nucleos(t)ides and acyclonucleotides.<smiles>CC1CC(OCCO)C(COP=O)O1</smiles>

dUMP<smiles>[R]/C(=C\CO)C[18OH]</smiles>

$\mathrm{R}=\mathrm{H}$ or $\mathrm{CH}_{2} \mathrm{OH}$

trans-butenyl

dUMP surrogate<smiles>OCC(F)=C(CO)CO</smiles>

F-trans-butenyl<smiles>[B]CC(F)=C(CO)CO</smiles>

previous work $\mathrm{B}=\mathrm{A}, \mathrm{U}, \mathrm{T}$

Figure 2: Acyclonucleotides as nucleotide surrogates.

nucleotide, will improve molecular recognition and activity. In addition, the polarity of the nucleotide and hydrogen-bond accepting capacity with proteins or enzymes would be restored [14].

The synthesis of fluoroalkene precursors of modified acyclonucleosides (VIII) has been explored by Choi, and more recently by us [15-17]. Nevertheless, it was reported that no antiviral activity for compounds of series VIII was observed due to the difficulty of phosphorylation of the substrate by kinases [16]. The first kinase phosphorylation step is generally rate limiting, and the prior introduction of a phosphate or phosphonate function can circumvent this problem. The preparation of diols VIII was realized by olefination of a protected 1,3-dihydroxypropanone (Figure 3). However, the selective introduction of functional groups is not possible in these diols as the two hydroxy groups present similar chemical reactivity. Other approaches are available for a selective preparation of monofluoroalkenes including olefination or defluorination reactions or a sigmatropic rearrangement, but these approaches are limited and do not allow the synthesis of tetrasubstituted fluoro- alkenes with good control of their geometry [18-21]. In order to develop a selective synthesis for tetrasubstituted fluoroalkenes we envisioned an alternative approach starting from fluoroalkylidene-oxetane derivatives and to the end we have studied the selectivity of the oxetane ring-opening reaction (Figure 3 ).

\section{Results and Discussion}

The preparation of a series of fluoroalkylidene-oxetanes 1-3 was previously reported from 3-oxetanone through an olefination reaction with benzothiazoyl sulfones (Scheme 1) [22]. With these fluoroalkylidene-oxetanes in hands, we studied the selectivity of ring-opening reactions with heteroatom nucleophiles in order to access tetrasubstituted fluoroalkenes. A control of the geometry of these reactions would allow ready access to novel fluorinated ACN precursors.

At the outset the opening of the oxetane ring of $\mathbf{1}$ by a range of nucleophiles was trialed under acidic conditions. Inspired by Yadav et al. [23], methanol (20 equiv) was used as nucleophile in the presence of camphorsulfonic acid (CSA, 1 equiv) in dichloromethane. The reaction was slow and required heating olefination

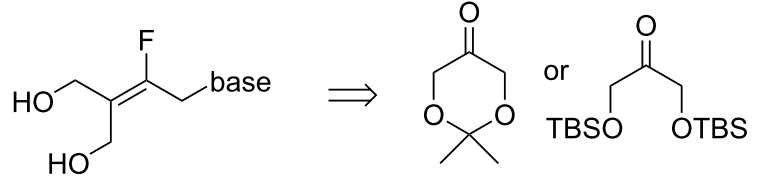

ring opening<smiles>O=C(CO)CC(F)=C(CO)C[18OH]</smiles> 

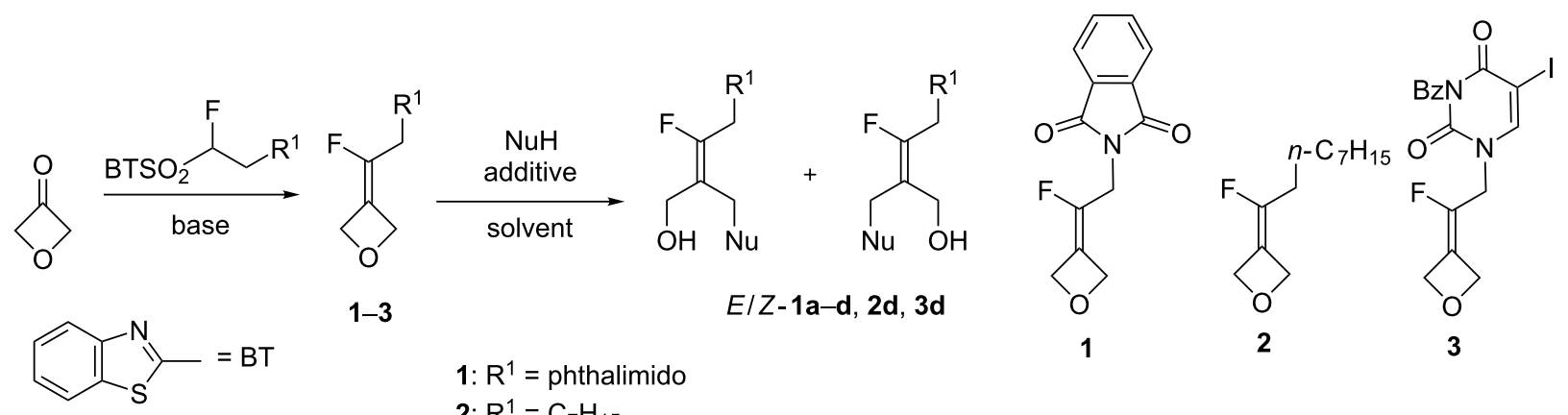

1: $\mathrm{R}^{1}=$ phthalimido

2: $\mathrm{R}^{1}=\mathrm{C}_{7} \mathrm{H}_{15}$

3: $\mathrm{R}^{1}=N^{3}-$ Bz-iodo-U

Scheme 1: Preparation of fluoroakylidene-oxetanes and their ring-opening reactions.

$\left(50-65{ }^{\circ} \mathrm{C}\right)$ for $26 \mathrm{~h}$ to reach a $75 \%$ conversion and afforded a mixture of $E / Z-1$ a in $60 \%$ yield. However, a low $E / Z$ selectivity (40:60) was observed (Table 1, entry 1 ). When using neat benzylic alcohol, completion was achieved after $20 \mathrm{~h}$ at $80{ }^{\circ} \mathrm{C}$ but again no substantial selectivity could be observed for product $1 \mathbf{b}$ (Table 1, entry 2). Inspired by the work of Müller and Wang [24,25], substitution by the more nucleophilic 2-mercaptobenzothiazol (BTSH, 1.4 equiv) was also possible in the presence of CSA ( 1 equiv) at $20{ }^{\circ} \mathrm{C}$ and an $80 \%$ conversion was reached after $24 \mathrm{~h}$. An improved $E / Z$ ratio of 25:75 was determined for this reaction and compound 1c was isolated in $65 \%$ yield (Table 1, entry 3 ). In this case the nucleophilic ringopening reaction appeared to be controlled by steric repulsions between the bulky benzothiazolyl and phthalimidoyl substituents affording preferentially the $Z$-isomer of 1c. However, heteronucleophiles such as sodium azide, secondary amine and cesium fluoride were unsuccessfully tested. Finally, using the conditions developed by Burkhard and Carreira [26], the opening of the fluoroalkylidene-oxetane ring was investigated with hydrobromic acid ( $\mathrm{HBr} 33$ wt \% in $\mathrm{AcOH}, 2.3$ equiv) in diethyl ether (Table 1, entry 4). This reaction proved faster and reached completion after $45 \mathrm{~min}$ at $20{ }^{\circ} \mathrm{C}$, giving product 1d with an excellent yield of $94 \%$ and an $E / Z$ selectivity of $89: 11$. The isomers could be separated and crystals of the major isomer were obtained by recrystallization. The X-ray diffraction analysis clearly showed that the bromine atom was located on the carbon trans to the fluorine atom resulting in the major product with the E-geometry (see Supporting Information File 1). It should be noted that longer reaction times resulted in slow solvolysis of alcohol $\mathbf{1 d}$ with acetic acid giving mainly the corresponding acetate (not shown). Product 1d was also obtained in a similar $E / Z$ ratio $(88: 12)$ when the ring-opening reaction

\begin{tabular}{|c|c|c|c|c|c|c|c|c|c|}
\hline entry & oxetane & $\begin{array}{l}\mathrm{Nu} \\
\text { (equiv) }\end{array}$ & $\begin{array}{l}\text { additive } \\
\text { (equiv) }\end{array}$ & $t(\mathrm{~h})$ & $T\left({ }^{\circ} \mathrm{C}\right)$ & solvent & product & $E / Z$ ratio $^{\mathrm{a}}$ & Yield $(\%)^{\mathrm{b}}$ \\
\hline 1 & 1 & $\begin{array}{l}\mathrm{MeOH} \\
(20)\end{array}$ & $\begin{array}{l}\text { CSA } \\
\text { (1) }\end{array}$ & 26 & 40 & $\mathrm{CH}_{2} \mathrm{Cl}_{2}$ & $1 a$ & $40: 60$ & 60 \\
\hline 2 & 1 & $\begin{array}{l}\mathrm{BnOH} \\
(24)\end{array}$ & $\begin{array}{l}\text { CSA } \\
(1)\end{array}$ & 20 & 80 & neat & $1 \mathrm{~b}$ & $45: 55$ & n.a. \\
\hline 3 & 1 & $\begin{array}{l}\text { BTSH } \\
(1.4)\end{array}$ & $\begin{array}{l}\text { CSA } \\
\text { (1) }\end{array}$ & 24 & 20 & $\mathrm{CH}_{2} \mathrm{Cl}_{2}$ & $1 c$ & $25: 75$ & 65 \\
\hline 4 & 1 & $\begin{array}{l}\mathrm{HBr} \\
(2.3)\end{array}$ & $\mathrm{AcOH}^{\mathrm{C}}$ & 0.75 & 20 & $\mathrm{Et}_{2} \mathrm{O}$ & $1 d$ & $89: 11$ & 94 \\
\hline 5 & 1 & $\begin{array}{l}\text { TBAB } \\
(2.5)\end{array}$ & $\begin{array}{l}\mathrm{BF}_{3} \cdot \mathrm{Et}_{2} \mathrm{O} \\
\text { (1.1) }\end{array}$ & 2 & -20 & $\mathrm{CH}_{2} \mathrm{Cl}_{2}$ & $1 d$ & $88: 12$ & 71 \\
\hline 6 & 2 & $\begin{array}{l}\mathrm{HBr} \\
(2.3)\end{array}$ & $\mathrm{AcOH}^{\mathrm{C}}$ & 0.75 & 20 & $\mathrm{CH}_{2} \mathrm{Cl}_{2}$ & 2d & $94: 6$ & 53 \\
\hline 7 & 3 & $\begin{array}{l}\mathrm{HBr} \\
(2.3)\end{array}$ & $\mathrm{AcOH}^{\mathrm{C}}$ & 0.75 & 20 & $\mathrm{CH}_{2} \mathrm{Cl}_{2}$ & - & - & - \\
\hline 8 & 3 & $\begin{array}{l}\text { TBAB } \\
(2.5)\end{array}$ & $\begin{array}{l}\mathrm{BF}_{3} \cdot \mathrm{Et}_{2} \mathrm{O} \\
(1.1)\end{array}$ & 2 & -20 & $\mathrm{CH}_{2} \mathrm{Cl}_{2}$ & $3 d$ & $96: 4$ & 76 \\
\hline
\end{tabular}

a Determined by ${ }^{19} \mathrm{~F}$ NMR of the crude mixture; byield of isolated product; ${ }^{\mathrm{C}} \mathrm{HBr} 33 \mathrm{wt} \%$ in $\mathrm{AcOH}$ solution. 
was performed in dichloromethane with tetrabutylammonium bromide (TBAB) as the bromide source and boron trifluoride diethyl etherate as an activator (Table 1, entry 5). Nevertheless, the isolated yield of the product decreased to $71 \%$. Next, the reaction performed with $\mathrm{HBr} / \mathrm{AcOH}$ was extended to alkylidene oxetanes substituted by an alkyl chain, and a pyrimidine base. The presence of the alkyl chain in place of the phthalimido group did not affect the selectivity observed with 1 . The ring opening reaction of the $n$-octyl substituted oxetane 2 resulted in an excellent selectivity of 94:6 towards the $E$-isomer of bromoalkylated product $\mathbf{2 d}$ (Table 1 , entry 6 ). The $E / Z$ mixture of $\mathbf{2 d}$ was isolated in moderate yield (53\%). In this case the corresponding acetate was observed as a minor product (15\%) but with a similar selectivity of 92:8, although it could not be isolated in pure form. Unfortunately, the introduction of a nucleic base such as $N^{3}$-benzoyliodouracil instead of the phthalimido group gave a complex mixture of products (Table 1, entry 7). In contrast, the ring-opening reaction was successful when performed in the presence of TBAB and $\mathrm{BF}_{3} \cdot \mathrm{Et}_{2} \mathrm{O}$ and afforded the $E$-alkene product 3d with good selectivity $(E / Z$ ratio $>96: 4)$ and $76 \%$ yield (Table 1 , entry 8$)$. The geometric assignment of compound 3d was corroborated by $1 \mathrm{D}$ NOESY experiments in which after selective irradiation of the protons $\alpha$ to the nitrogen atom, a response was observed only for the protons $\alpha$ to the bromine atom, thus indicating their spatial proximity.

In order to elucidate the selectivity control in this ring-opening reaction displayed by bromide ion despite the presence of bulky substituents (phthalimido and alkyl groups), a comparative study was initiated using non-fluorinated alkylidene oxetanes as substrates. Since the oxetane ring was attacked from the side of the bulky phthalimide or alkyl chain, it appeared plausible that the selectivity observed for the reaction did not originate from steric hindrance. Accordingly, the electronic influence of fluorine was explored. Thus, the non-fluorinated analogues bearing a phthalimido group (4) and an alkyl chain (5) were synthesized, and submitted to the ring-opening reaction [27,28]. Pleasingly, when subjecting compound 4 to the previous reaction conditions, a single isomer of bromoalcohol $\mathbf{4 d}$ formed (determined by ${ }^{1} \mathrm{H}$ NMR of the crude) and the product was isolated in an excellent yield of $94 \%$ (Table 2 , entry 3 ). The geometry of the product was confirmed to be $E-\mathbf{4 d}$ by X-ray diffraction analysis (see Supporting Information File 1). The attack of the bromide ion this time occurred from the side of the alkene hydrogen atom (cis attack) and away from the bulky phthalimido group giving solely product $E-\mathbf{4 d}$. Likewise, the reaction of the alkyl-substituted substrate $\mathbf{5}$ proceeded with excellent $E$-selectivity (as determined by ${ }^{1} \mathrm{H}$ NMR of the crude). As in case of the fluorinated analogue, a substantial part of the newly formed alcohol $\mathbf{5 d}$ reacted with acetic acid forming the corresponding acetate 5d'. Interestingly, it appeared that only the $E$-isomer of 5d reacted with $\mathrm{AcOH}$ giving pure $E$-5d' in $44 \%$ isolated yield. This left an 81:19E/Z mixture of $\mathbf{5 d}$ from which the pure alcohol $E$-5d could be isolated in 34\% yield (Table 2, entry 4). The overall $E / Z$ ratio for the ring-opening reaction of 5 was 91:9. 1D NOESY experiments were performed with alcohol $\mathbf{5 d}$ and the outcome indicated that the bromide attack took place away from the bulky alkyl chain, resulting in the observed $E$-selectivity. These outcomes were opposite to those obtained

Table 2: Selectivity in the presence or absence of the fluorine atom.

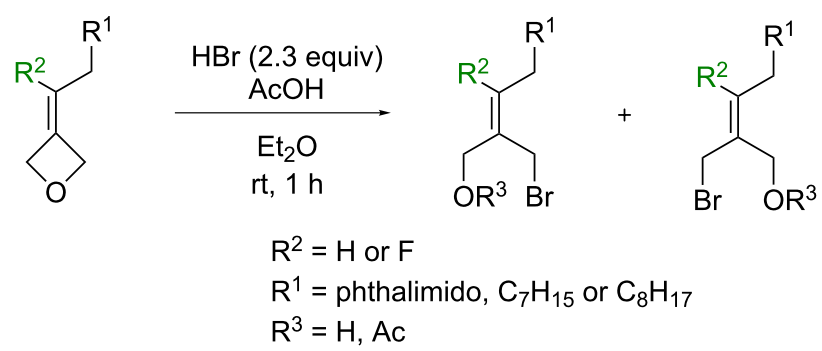

\begin{tabular}{|c|c|c|c|c|c|c|c|}
\hline entry & substrate & $\mathrm{R}^{2}$ & $\mathrm{R}^{1}$ & $\mathrm{R}^{3}$ & product & $E / Z$ ratio $^{a}$ & yield $(\%)^{b}$ \\
\hline 1 & 1 & $F$ & phthalimido & $\mathrm{H}$ & 1d & $89: 11$ & 94 \\
\hline 2 & 2 & $F$ & $\mathrm{C}_{7} \mathrm{H}_{15}$ & $\mathrm{H}$ & 2d & $94: 6$ & 53 \\
\hline 3 & $4^{c}$ & $\mathrm{H}$ & phthalimido & $\mathrm{H}$ & $4 d$ & $100: 0$ & 94 \\
\hline \multirow[t]{2}{*}{4} & 5 & $\mathrm{H}$ & $\mathrm{C}_{8} \mathrm{H}_{17}$ & $\mathrm{H}$ & $5 d$ & $81: 19$ & $34^{d}$ \\
\hline & & & & Ac & $5 d^{\prime}$ & $100: 0$ & 44 \\
\hline
\end{tabular}

${ }^{a}$ Determined by ${ }^{19} \mathrm{~F}$ NMR $(\mathbf{1}, \mathbf{2})$ or ${ }^{1} \mathrm{H}$ NMR $(\mathbf{4}, \mathbf{5})$ of the crude mixture; byield of isolated product; ${ }^{\text {csubstrate }} \mathbf{4}$ was contaminated with 1 molar equivalent of phthalimide; dyield of isolated $E-5 \mathbf{d}$. 
with the fluorinated substrate series, consistent with steric hindrance governing the non-fluorine containing oxetane reactions but electronics influencing and reversing the regioselectivity of the fluoro-oxetane reactions.

The reaction was then extended to fluoroalkylidene-oxetane $\mathbf{8}$ to expand the range of tetrasubstituted fluoroalkenes accessible via this method (Scheme 2). A variety of conditions were explored to prepare the protected alcohol $\mathbf{8}$ including an unsuccessful reduction of the corresponding ethyl ester (vide infra, 12). Then we turned our attention to the modified Julia reaction since the reduction of the ester functionality could be achieved at the sulfide stage [29], prior to its oxidation to give $\mathbf{6}$. Alcohol $\mathbf{6}$ was not stable in basic medium, as a Smiles rearrangement occurred leading to fluoroethylene and benzothiazolone. Therefore, its benzylation was explored under acidic conditions with benzyl trichloroacetimidate (1.5 equiv) and a catalytic amount of trifluoromethanesulfonic acid. This gave benzyl ether 7 as a 2.5:1 mixture with $N$-benzylbenzothiazolone (not shown, Scheme 2). After purification, benzyl ether $\mathbf{7}$ was successfully subjected to the modified Julia olefination conditions with 3-oxetanone, to give the corresponding alkene $\mathbf{8}$ in $79 \%$ yield.
With alkene 8 in hand, the ring-opening reaction was explored in the presence of hydrobromic acid ( $\mathrm{HBr} 33 \mathrm{wt} \%$ in $\mathrm{AcOH})$ in diethyl ether (Table 3). As observed with the phthalimido group, the reaction led to alkene $E-\mathbf{9}$ as the major product, together with alkene $Z-9$ and a third product that was identified as the 2,5-dihydrofuran derivative $\mathbf{1 0}$.

Using the standardized conditions, but at a temperature of $0{ }^{\circ} \mathrm{C}$ instead of $20^{\circ} \mathrm{C}$, for $30 \mathrm{~min}$, complete conversion was achieved and the three products $E, Z-\mathbf{9}$ and $\mathbf{1 0}$ were present in a $62: 8: 26$ ratio as determined by ${ }^{19} \mathrm{~F}$ NMR, the remaining $4 \%$ being attributed to acetylated analogues of $\mathbf{9}$ (Table 3, entry 1). After purification, two products were obtained as a 95:5 mixture and identified by NMR as the desired bromoalcohols $E-\mathbf{9}$ and $Z-9$, respectively. The selectivity of the oxetane ring opening (crude $E / Z$ ratio: $89: 11)$ was again governed by the presence of the fluorine atom and not by steric hindrance.

In order to limit the competitive formation of the heterocyclic ether 10, the addition of TBAB as a bromide source was explored. To our delight, after $30 \mathrm{~min}$ at $0{ }^{\circ} \mathrm{C}$, the crude ${ }^{19}$ F NMR showed that only $4 \%$ of $\mathbf{1 0}$ and $96 \%$ of $\mathbf{9}$ as an $84: 16$

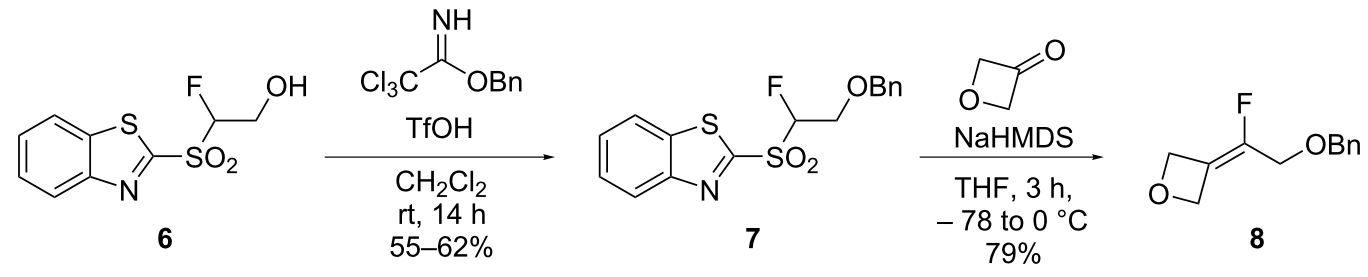

Scheme 2: Synthesis of benzyloxy-substituted fluoroethylidene-oxetane derivative 8.

Table 3: Opening of the benzyloxy-substituted fluoroethylideneoxetane derivative 8

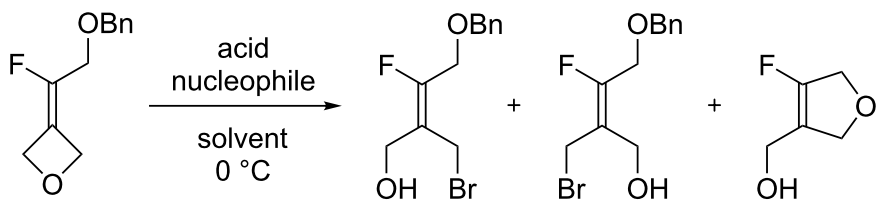

8

E-9

Z-9

10

\begin{tabular}{|c|c|c|c|c|c|c|c|c|}
\hline \multirow[t]{2}{*}{ Entry } & \multirow[t]{2}{*}{ Nu (equiv) } & \multirow{2}{*}{$\begin{array}{l}\text { Additive } \\
\text { (equiv) }\end{array}$} & \multirow[t]{2}{*}{ Solvent } & \multirow{2}{*}{$\begin{array}{l}\text { Reaction } \\
\text { time }(\mathrm{h})\end{array}$} & \multicolumn{3}{|c|}{ Selectivity $^{a}$} & \multirow[t]{2}{*}{ Yield of $9(\%)$} \\
\hline & & & & & $E-9$ & $Z-9$ & 10 & \\
\hline 1 & $\mathrm{HBr}(2.3)$ & $\mathrm{AcOH}$ & $\mathrm{Et}_{2} \mathrm{O}$ & 0.5 & 62 & 8 & 26 & 45 \\
\hline 2 & $\begin{array}{l}\operatorname{HBr}(1.2) \\
\operatorname{TBAB}(2.5)\end{array}$ & $\mathrm{AcOH}$ & $\mathrm{CH}_{2} \mathrm{Cl}_{2}$ & 0.5 & 81 & 15 & 4 & $74^{b}$ \\
\hline 3 & TBAB (2.5) & $\mathrm{BF}_{3} \cdot \mathrm{OEt}_{2}(1.1)$ & $\mathrm{CH}_{2} \mathrm{Cl}_{2}$ & 1 & 90 & 10 & 0 & 66 \\
\hline
\end{tabular}

${ }^{\text {aDDetermined by }}{ }^{19} \mathrm{~F}$ NMR of the crude mixture; byield for the $92: 8 \mathrm{E} / Z$ mixture. 
$E / Z$ mixture had formed (Table 3, entry 2). Separation of the two $E / Z$ isomers proved challenging by column chromatography and a $92: 8$ mixture of $E / Z-9$ was obtained in $74 \%$ yield. Finally, the reaction performed with TBAB in the presence of $\mathrm{BF}_{3} \cdot \mathrm{Et}_{2} \mathrm{O}$ afforded only alkenes 9 with an excellent $E$-selectivity and in $66 \%$ yield (Table 3 , entry 3 ). In this case, we presume 10 was not obtained because the benzyl ether is not nucleophilic enough to react due to it complexation by $\mathrm{BF}_{3} \cdot \mathrm{OEt}_{2}$

To understand in more detail the competitive formation of linear versus cyclic products in the reaction, methanol was explored as the nucleophile instead of bromide ion (Scheme 3). The reaction $\left(43 \mathrm{~h}, 20^{\circ} \mathrm{C}\right)$ realized in $\mathrm{MeOH}$ as a solvent and in the presence of CSA ( 1 equiv) afforded a mixture of $\mathbf{1 0}(85 \%)$ and the expected methoxyalcohols $11(10 \%, 1: 1 \mathrm{E} / \mathrm{Z}$ ratio) in addition to starting fluoroalkylidene-oxetane $8(5 \%)$. After purification, compound $\mathbf{1 0}$ was isolated in $75 \%$ yield.

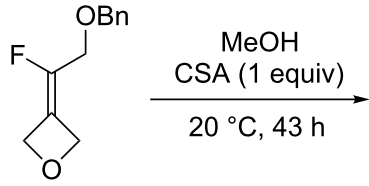

8<smiles>COCC(CO)=C(F)COc1ccccc1</smiles>

11
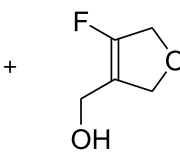

$10(75 \%)$

Scheme 3: Effect of the medium on the selective formation of derivative 10 .

The results from the acid-catalyzed results support the reaction outcomes which depended on the nucleophile (methanol or bromide ion) (Scheme 4). In the presence of excess bromide ions, the direct intermolecular nucleophilic attack of the oxetane (path a) is preferred leading to bromoalcohol 9 (path a). On the other hand, in the presence of the weaker methanol nucleophile, an intramolecular ring-opening reaction by the benzyl ether oxygen is preferred leading to the 2,5-dihydrofuran 10 (path b)

Finally, we turned our attention to a last series of reactions exploring the ring-opening reaction of fluoroalkylidene-oxetane 12 (Table 4).

Given the previous results, in the presence of the ester function we expected the ring-opening reaction to proceed with the formation of additional products to alkenes $E-13$ and $Z-13$. In fact, two byproducts formed and were identified as $\beta$-hydroxymethyl- $\alpha$-fluorolactone $\mathbf{1 4}$ and $\beta$-bromomethyl- $\alpha$-fluorolactone 15 (Table 4) [30]. This ring expansion has been already reported in the literature from oxetane-containing $\alpha, \beta$-unsaturated carbonyl derivatives through a Lewis acid-catalyzed rearrangement [31]. When the previous conditions $(\mathrm{HBr} / \mathrm{AcOH})$ were tried $\left(3.5 \mathrm{~h}, 0{ }^{\circ} \mathrm{C}\right.$ to $\left.20{ }^{\circ} \mathrm{C}\right)$, hydroxymethyllactone $14(87 \%$, Table 4, entry 1) was the main product with traces of the corresponding acetate (4\%, not shown), the bromomethyllactone 15 (8\%), and alkene $Z-13$ (1\%). Only lactone 14 could be isolated in a pure form (58\% yield). The amount of $\mathrm{HBr} / \mathrm{AcOH}$ had little influence on the selectivity (Table 4 , entry 2) of the reaction. However, in the presence of TBAB (2.5 equiv) and CSA (2 equiv) an $84 \%$ conversion into mainly brominated lactone 15 (79\%) with traces of hydroxylated lactone $\mathbf{1 4}$, and of bromoalkene $Z-\mathbf{1 3}$ was determined by crude ${ }^{19} \mathrm{~F}$ NMR. The remaining $8 \%$ appeared to be the $\beta$-chloromethyllactone 19 (see Scheme 7 below), an analogue of $\mathbf{1 5}$ as determined by NMR analysis and supported by HRMS. All three halogenated products were purified and isolated as a mixture $(\approx 61 \%$ determined by NMR). The contrasting result observed with $\mathrm{HBr} / \mathrm{AcOH}$ and $\mathrm{TBAB} / \mathrm{CSA}$ highlighted the importance of the acidity of the medium on the reaction course of the ring-opening reaction (Scheme 5). The former, using an excess of acid (33\% $\mathrm{HBr}$ in AcOH solution) favored the direct nucleophilic attack (path $b$ ) leading to lactone $\mathbf{1 4}$, whereas the latter in the presence of $\mathrm{TBAB} / \mathrm{CSA}$ allowed bromide addition on the same side of the fluorine atom (path a) leading to lactone 15 [31]. However, the reaction can be stopped at the alcohol stage when performed in the presence of $\mathrm{BF}_{3} \cdot \mathrm{Et}_{2} \mathrm{O}$ instead of CSA to afford alkene Z-13 as the major product. The use of boron trifluoride etherate as an activator combined with TBAB afforded exclusively alkene Z-13 as evidenced by TLC, but after work-up, $22 \%$ of the bromomethyllactone 15 was observed (Table 4, entry 4). It appeared obvious that $Z \mathbf{- 1 3}$ could cyclize under acidic conditions and during the purification gave $\beta$-bromomethyllactone 15. This was later confirmed when various ester/lactone mixtures obtained after the ring-opening reaction were treated with<smiles>OC/C(CBr)=C(/CBr)COc1ccccc1</smiles>

E-9

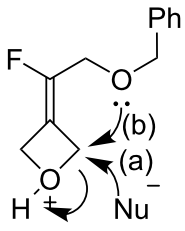

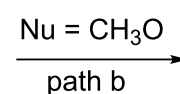<smiles>COCc1ccccc1</smiles>

10 
Table 4: Ring-opening reaction from acetate derivative 12.

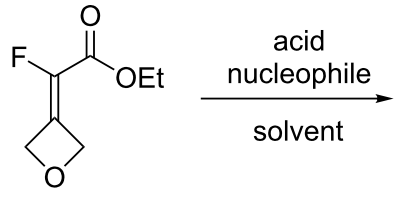

12<smiles>CCOC(=O)/C(F)=C(/CO)CBr</smiles>

$E-13$<smiles>O=C1OCC(CO)=C1F</smiles>

14<smiles>CCOC(=O)/C(F)=C(\CO)CBr</smiles>

Z-13<smiles>O=C1OCC(CBr)=C1F</smiles>

15

\begin{tabular}{|c|c|c|c|c|c|c|c|c|c|c|}
\hline \multirow[t]{2}{*}{ entry } & \multirow[t]{2}{*}{$\mathrm{Nu}$ (equiv) } & \multirow[t]{2}{*}{ additive } & \multirow[t]{2}{*}{ solvent } & \multirow[t]{2}{*}{$t(\mathrm{~h})$} & \multirow[t]{2}{*}{$T\left({ }^{\circ} \mathrm{C}\right)$} & \multicolumn{4}{|c|}{ selectivity $^{a}$} & \multirow{2}{*}{$\begin{array}{l}\text { product } \\
(\text { yield })^{b}\end{array}$} \\
\hline & & & & & & $E-13$ & 14 & $Z-13$ & 15 & \\
\hline 1 & $\mathrm{HBr}(2.5)$ & $\mathrm{AcOH}$ & $\mathrm{Et}_{2} \mathrm{O}$ & 3.5 & 20 & - & 87 & 1 & 8 & $14(58)$ \\
\hline 2 & $\mathrm{HBr}(1.2)$ & $\mathrm{AcOH}$ & $\mathrm{Et}_{2} \mathrm{O}$ & 3.5 & 0 & 3 & 76 & 7 & 10 & - \\
\hline 3 & TBAB (2.5) & $\operatorname{CSA}(2)^{c}$ & $\mathrm{CH}_{2} \mathrm{Cl}_{2}$ & 30 & 20 & - & 7 & 6 & $79(8)^{d}$ & $15(61)^{\mathrm{e}}$ \\
\hline 4 & TBAB (2) & $\mathrm{BF}_{3} . \mathrm{OEt}_{2}(1.5)$ & $\mathrm{CH}_{2} \mathrm{Cl}_{2}$ & 4 & -20 & - & - & 78 & 22 & $\begin{array}{l}Z-13(72)^{f} \\
15(21)^{f}\end{array}$ \\
\hline 5 & TBAB (1.5) & - & $\mathrm{CH}_{2} \mathrm{Cl}_{2}$ & 16 & 20 & - & - & - & - & - \\
\hline 6 & - & $\mathrm{BF}_{3} \cdot \mathrm{OEt}_{2}(1)$ & $\mathrm{CH}_{2} \mathrm{Cl}_{2}$ & 2 & 20 & - & 100 & - & - & $14(67)$ \\
\hline
\end{tabular}

aDetermined by ${ }^{19} \mathrm{~F}$ NMR of the crude mixture; bisolated yield; cthe 2 nd equivalent of CSA was added after $24 \mathrm{~h}$; ${ }^{\mathrm{d}}$ chlorinated instead of brominated products; ${ }^{e}$ yield of an $87: 8: 5$ mixture of products $15 / 19 / Z-13 ;{ }^{f} Z-13$ and 15 were obtained as a crude mixture, yields were calculated from the crude mass and ${ }^{1} \mathrm{H}$ NMR.

acid (PTSA) in $\mathrm{Et}_{2} \mathrm{O}$ giving pure lactone $\mathbf{1 5}$ or at least enriched mixtures depending on the reaction times (Scheme 5).

As a control, 12 was shown to be unreactive to $\mathrm{TBAB}$ on its own (Table 4, entry 5). Once again, the effect of the fluorine atom was highlighted by an investigation with the non-fluorinated alkylidene oxetane 16. The latter was subjected to the $\mathrm{HBr} / \mathrm{AcOH}$ ring-opening reaction conditions (Scheme 6). Remarkably, the cyclic products $\beta$-hydroxymethyl and $\beta$-bromomethyl- $\gamma$-lactones $\mathbf{1 7}$ and $\mathbf{1 8}$ were obtained in an 8:92 ratio [32]. This complete reversal of selectivity in comparison with fluoroalkylidene-oxetane 12, where the $\beta$-hydroxymethyl$\gamma$-lactone 14 was obtained, confirmed an electronic influence of the fluorine atom on these ring-opening reactions (Table 3 , entries 1 and 2). In the case of fluoroalkylidene-oxetane 12 and, in contrast with 16, when subjected to $\mathrm{HBr} / \mathrm{AcOH}$, the elec- tronic repulsion induced between fluorine and bromine limited the intermolecular ring-opening reaction by bromide in favor of a faster intramolecular reaction involving the ester group leading to 14. Indeed, a competitive cyclization reaction occurred forming 14 with $\mathrm{HBr} / \mathrm{AcOH}$ and confirmed when the reaction was performed in the presence of $\mathrm{BF}_{3} \cdot \mathrm{Et}_{2} \mathrm{O}$ only

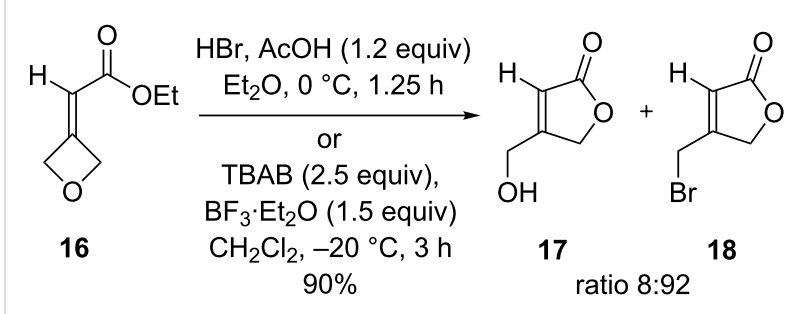

Scheme 6: Opening reaction of ethyl 2-(oxetanyl-3-idene)acetate (16).

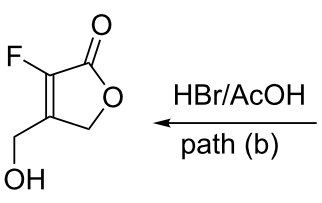

14

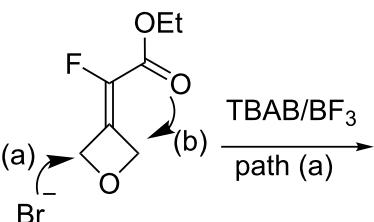

12<smiles>CCOC(=O)/C(F)=C(\CO)CBr</smiles><smiles>O=C1OCC(CBr)=C1F</smiles>

15

TBAB/CSA 
(Table 4, entries 1, 2, and 6). Of note in contrast to 8 , when $\mathrm{TBAB} / \mathrm{BF}_{3} \cdot \mathrm{Et}_{2} \mathrm{O}$ was added we cannot exclude a control by steric or electronic repulsions between bromide ions and the ester function leading to $Z-\mathbf{1 3}$ and $\mathbf{1 5}$ instead of expected alkene $E-\mathbf{1 3}$ and to the lactone $\mathbf{1 8}$ from alkylidene oxetanes $\mathbf{1 2}$ and 16, respectively.

Having established selective approaches for the preparation of halogenated allylic fluoroalkenes, their use in the synthesis of highly functionalized tetrasubstituted fluoroalkenes was explored. The derivatization of the three brominated products, lactone $\mathbf{1 5}$ and alkenes $E$-1d and $E$-9, was studied either on the bromomethyl $\left(\mathrm{CH}_{2} \mathrm{Br}\right)$ or on the hydroxymethyl $\left(\mathrm{CH}_{2} \mathrm{OH}\right)$ arm, when applicable.

First, from a mixture of lactones $\mathbf{1 5}$ and $\mathbf{1 9}$ substitution on the bromomethyl arm was performed using sodium azide (Scheme 7). The reaction proceeded smoothly in DMF but it proved difficult to extract product $\mathbf{2 0}$ from water. When the reaction was performed in acetone this allowed for a simple filtration of the sodium chloride and bromide salts formed and resulted in very satisfactory yields (91-97\%) after column chromatography. An Arbuzov phosphonylation was performed on the crude lactone product 15 (containing $10 \%$ of ester $Z-\mathbf{1 3}$ ) and proved successful with phosphonolactone $\mathbf{2 1}$ being isolated in $77 \%$ yield after column chromatography (Scheme 7). To access tetrasubstituted alkenes, reduction of $\mathbf{2 1}$ to generate diol $\mathbf{2 2}$ was explored with lithium borohydride in $\mathrm{Et}_{2} \mathrm{O}$. However, the reaction was slow at $20{ }^{\circ} \mathrm{C}$ and did not progress beyond $50 \%$ conversion even after the addition of excess $\mathrm{LiBH}_{4}$. After purification by flash chromatography starting lactone $\mathbf{2 1}$ was obtained in $49 \%$ yield and the desired diol 22 in $47 \%$ yield. When the reaction was carried out in refluxing THF, a complete conversion was achieved but also with impurities. This route was not investigated further, and instead functionalization of alkene $E$-1d was explored.

Direct ring-opening reactions of fluoroalkylidene-oxetane 1 with heteronucleophiles were previously explored and success was only possible with thiols, such as mercaptobenzothiazole (Table 1). However, the reaction was not selective and afforded a mixture of $E / Z$ alkenes 1c. The functionalization of alkene $E$-1d via displacement of the bromine atom (Scheme 8), with nucleophiles such as $\mathrm{CsF}$ and $\mathrm{NaN}_{3}$ was then studied. When the reaction was performed in DMF products $E-\mathbf{2 3}$ and $Z$-24 were generated in $92 \%$ and $93 \%$ yield, respectively. Reactions with amines and thiols such as pyrrolidine and 2-mercaptobenzothiazole, gave rise to the products $Z-25$ and $E-\mathbf{1 c}$ in $96 \%$ yield, respectively. These reactions were carried out in dichloromethane in the presence of $\mathrm{Et}_{3} \mathrm{~N}$. It should be noted that following this two-step method, pure $E$-1c could be obtained while direct ring opening of $\mathbf{1}$ with BTSH and CSA resulted in a 25:75 mixture of E/Z-1c. A crystallographic analysis of crystals of Z-25 confirmed the nature and geometry of the obtained product (see Supporting Information File 2). Addition of carbanions or alcoholates was also attempted but the starting bromide $E$-1d degraded under these conditions.

Finally, this expeditious synthesis of tetrasubstituted fluoroalkenes by sequential ring-opening and nucleophilic substitution reactions was applied to test the robustness of a selective preparation of precursors of ACN (VII) bearing different functional groups (Scheme 9). A particular focus was applied to the preparation of the phosphonate 29, a precursor of VII that is not accessible from diol VIII.

First, starting from pure alkene $E-9$, the introduction of a protected alcohol as a mimic of the naturally occurring

a) azidation<smiles>O=C1OCC(CBr)=C1F</smiles><smiles>[13CH3]</smiles><smiles>O=C1OCC(CCl)=C1F</smiles>

19

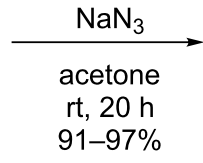
or $67: 33$

b) phosphonylation<smiles>O=C1OCC(CBr)=C1F</smiles>

15

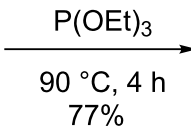
$77 \%$<smiles>CCOP(=O)(CC1=C(F)C(=O)OC1)OCC</smiles>

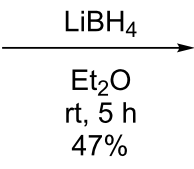

20 


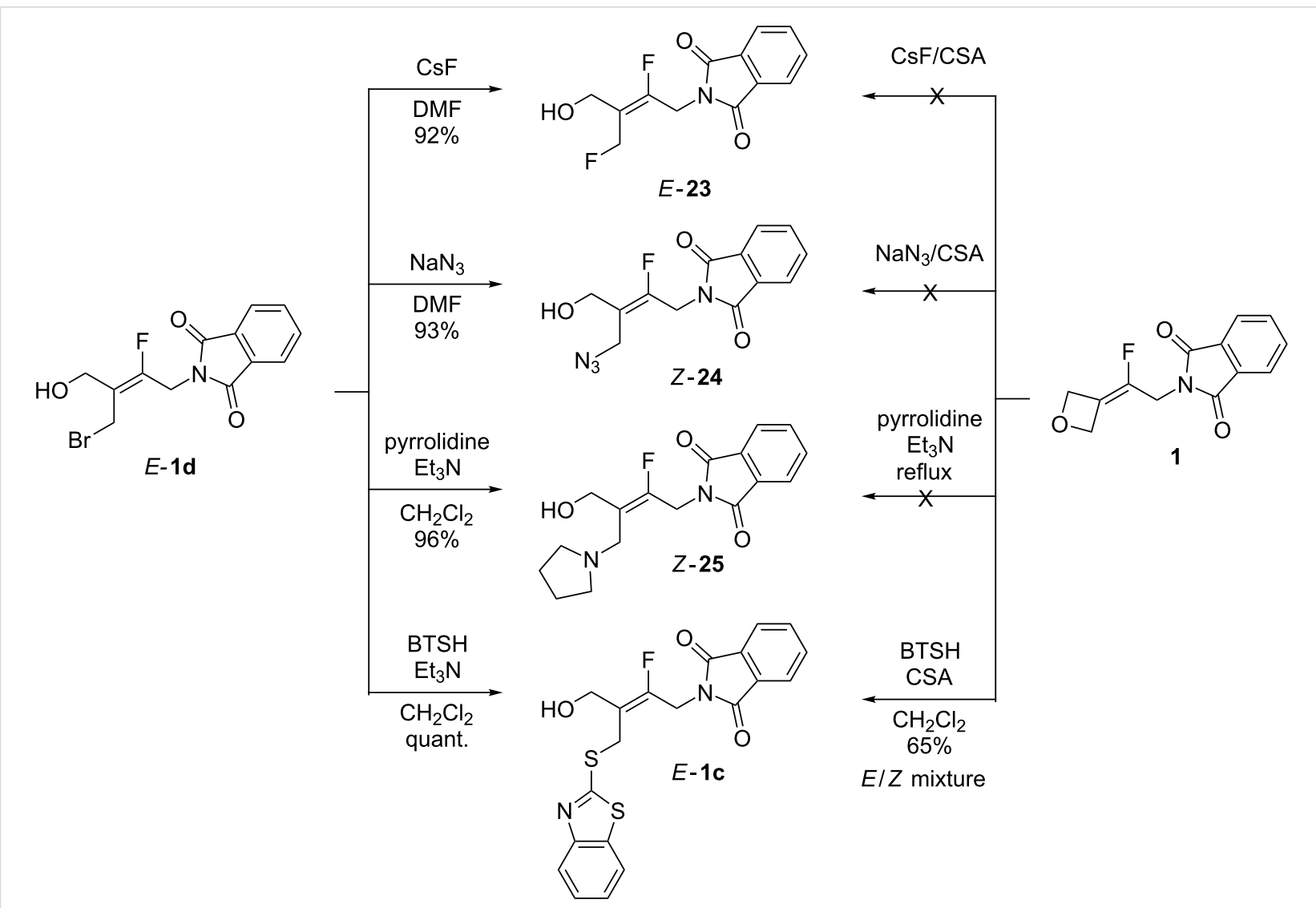

Scheme 8: Functionalization by substitution reaction of the bromide $E$-1d vs ring-opening reaction of the oxetane 1 .

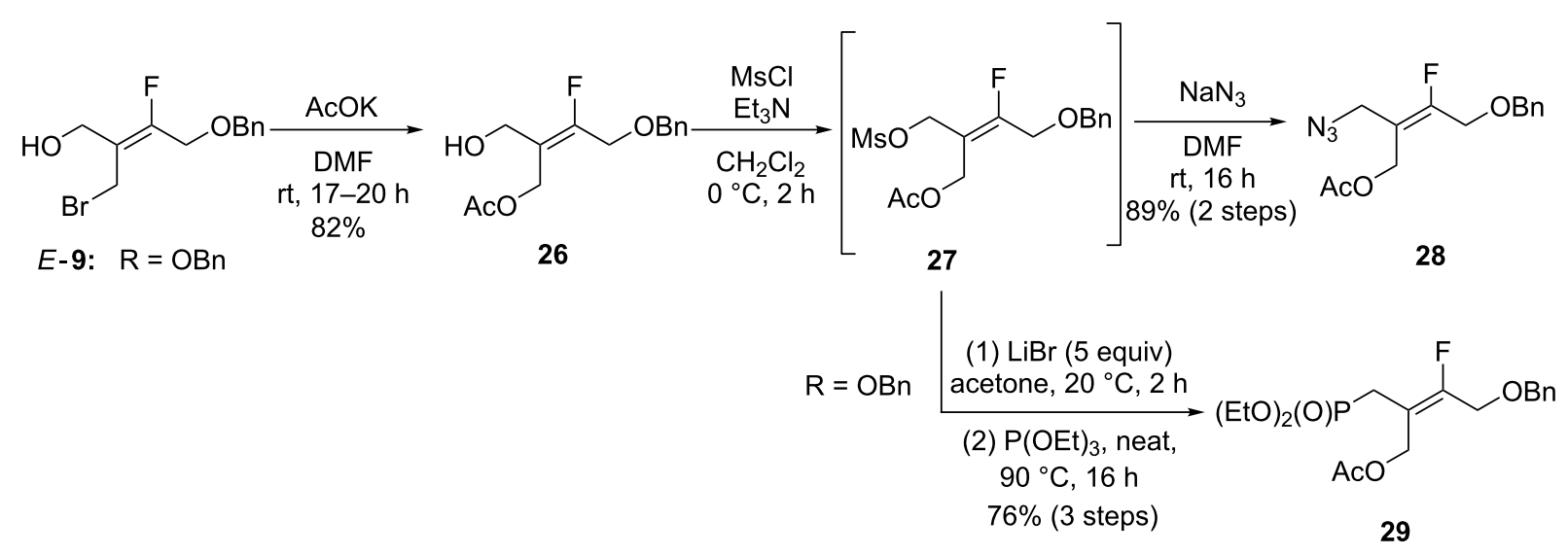

Scheme 9: Preparation of tetrasubstituted fluoroalkenes.

3'-hydroxy group was achieved by allylic bromine displacement with AcOK to efficiently afford alkene 26. The phosphonate was introduced in three steps through the formation of intermediate mesylate 27 . This mesylate was progressed without purification, albeit contaminated $(10 \%)$ with the corresponding chloride (not shown). An Arbuzov reaction was performed directly on the allylic bromide obtained by treatment of
27 with $\mathrm{LiBr}$ ( 5 equiv), to give the phosphonate $\mathbf{2 9}$ in $76 \%$ overall yield. Finally, azide $\mathbf{2 8}$ was obtained in $89 \%$ yield in two steps from the non-isolated intermediate mesylate 27. After deacetylation, 28 was readily converted to $E-\mathbf{2 4}$ (see Scheme 8). These transformations of alkene $E-9$ illustrated how the geometry can be controlled for the preparation of tetrasubstituted fluoroalkenes. The synthesis of nucleotide mimics from either 
phosphonate $\mathbf{2 9}$ or azide $\mathbf{2 8}$ is underway and will be reported in due course.

\section{Conclusion}

The selective synthesis of tetrasubstituted $E$ - or $Z$-fluoroalkenes was achieved by ring-opening reactions of fluoroalkylideneoxetanes, with the presence of the fluorine atom governing regioisomeric attack of the bromide ion. Functionalization of the resultant bromoalcohols with nucleophiles led, in two steps from oxetanes, to a series of highly functionalized tetrasubstituted fluoroalkenes with excellent geometric control. This method offers ready access to novel fluoroalkenes as potential precursors of important drug mimics.

\section{Supporting Information}

The experimental section describing the preparation of all new compounds, the copies of the NMR data $\left({ }^{1} \mathrm{H}\right.$ NMR,

${ }^{13} \mathrm{C}$ NMR, ${ }^{19} \mathrm{~F}$ NMR), HOESY and NOESY experiments and crystallographic data for compounds $1 \mathrm{~d}, \mathbf{4 d}$ and 25.

The CIF files of $\mathbf{1 d}, \mathbf{4 d}$ and $\mathbf{2 5}$.

\section{Supporting Information File 1}

Experimental section and copies of spectra.

[https://www.beilstein-journals.org/bjoc/content/

supplementary/1860-5397-16-160-S1.pdf]

\section{Supporting Information File 2}

Crystallographic data (cif) for compounds $E-\mathbf{1 d}, E-\mathbf{4 d}$, and Z-25.

[https://www.beilstein-journals.org/bjoc/content/ supplementary/1860-5397-16-160-S2.zip]

\section{Funding}

This work was supported by the excellence laboratory LabEx SYNORG (ANR-11-LABX-0029), ANR funding DALATAR (ANR-19-CE18-0008-03) the Conseil Régional de Normandie and the European FEDER funding.

\section{ORCID ${ }^{\circledR} \mathrm{iDs}$}

Clément Q. Fontenelle - https://orcid.org/0000-0002-1630-3407

Thibault Thierry - https://orcid.org/0000-0003-0342-2391

Romain Laporte - https://orcid.org/0000-0002-5984-6794

Emmanuel Pfund - https://orcid.org/0000-0003-1896-0109

Thierry Lequeux - https://orcid.org/0000-0003-3783-4458

\section{References}

1. Zhou, Y.; Wang, J.; Gu, Z.; Wang, S.; Zhu, W.; Aceña, J. L.; Soloshonok, V. A.; Izawa, K.; Liu, H. Chem. Rev. 2016, 116, 422-518. doi:10.1021/acs.chemrev.5b00392
2. Purser, S.; Moore, P. R.; Swallow, S.; Gouverneur, V. Chem. Soc. Rev. 2008, 37, 320-330. doi:10.1039/b610213c

3. Gillis, E. P.; Eastman, K. J.; Hill, M. D.; Donnelly, D. J.; Meanwell, N. A. J. Med. Chem. 2015, 58, 8315-8359. doi:10.1021/acs.jmedchem.5b00258

4. O'Hagan, D. J. Fluorine Chem. 2010, 131, 1071-1081. doi:10.1016/j.jfluchem.2010.03.003

5. Len, C.; Mackenzie, G. Tetrahedron 2006, 62, 9085-9107. doi:10.1016/j.tet.2006.07.050

6. Bassetto, M.; Slusarczyk, M. Pharm. Pat. Anal. 2018, 7, 277-299. doi:10.4155/ppa-2018-0028

7. Xie, M.-S.; Niu, H.-Y.; Qu, G.-R.; Guo, H.-M. Tetrahedron Lett. 2014, 55, 7156-7166. doi:10.1016/j.tetlet.2014.11.060

8. De Clercq, E. Med. Res. Rev. 2013, 33, 1278-1303. doi:10.1002/med.21283

9. Schramm, V. L. Chem. Rev. 2018, 118, 11194-11258. doi:10.1021/acs.chemrev.8b00369

10. Kasthuri, M.; El Amri, C.; Lefort, V.; Périgaud, C.; Peyrottes, S New J. Chem. 2014, 38, 4736-4742. doi:10.1039/c4nj00813h

11. Topalis, D.; Pradère, U.; Roy, V.; Caillat, C.; Azzouzi, A.; Broggi, J.; Snoeck, R.; Andrei, G.; Lin, J.; Eriksson, S.; Alexandre, J. A. C.; El-Amri, C.; Deville-Bonne, D.; Meyer, P.; Balzarini, J.; Agrofoglio, L. A. J. Med. Chem. 2011, 54, 222-232. doi:10.1021/jm1011462

12. Amblard, F.; Nolan, S. P.; Schinazi, R. F.; Agrofoglio, L. A. Tetrahedron 2005, 61, 537-544. doi:10.1016/j.tet.2004.11.019

13. Varada, M.; Erande, N. D.; Kumar, V. A. RSC Adv. 2015, 5, 97824-97830. doi:10.1039/c5ra15673d

14. Champagne, P. A.; Desroches, J.; Paquin, J.-F. Synthesis 2015, 47 , 306-322. doi:10.1055/s-0034-1379537

15. Choi, M.-H.; Lee, C.-K.; Jeong, L. S.; Chun, M. W.; Kim, H.-D. Nucleosides, Nucleotides Nucleic Acids 2001, 20, 681-684. doi: $10.1081 / \mathrm{ncn}-100002350$

16. Choi, M.-H.; Kim, H.-D. Arch. Pharmacal Res. 1997, 20, 501-506. doi:10.1007/bf02973948

17. Prunier, A.; Calata, C.; Legros, J.; Maddaluno, J.; Pfund, E.; Lequeux, T. J. Org. Chem. 2013, 78, 8083-8097. doi:10.1021/j0401356j

18. Drouin, M.; Hamel, J.-D.; Paquin, J.-F. Synthesis 2018, 50, 881-955. doi:10.1055/s-0036-1591867

19. Landelle, G.; Bergeron, M.; Turcotte-Savard, M.-O.; Paquin, J.-F. Chem. Soc. Rev. 2011, 40, 2867-2908. doi:10.1039/c0cs00201a

20. Yanai, H.; Taguchi, T. Eur. J. Org. Chem. 2011, 5939-5954. doi:10.1002/ejoc.201100495

21. Pfund, E.; Lequeux, T.; Gueyrard, D. Synthesis 2015, 47, 1534-1546. doi:10.1055/s-0034-1380548

22. Laporte, R.; Prunier, A.; Pfund, E.; Roy, V.; Agrofoglio, L. A.; Lequeux, T. Eur. J. Org. Chem. 2015, 3121-3128. doi:10.1002/ejoc.201500172

23. Yadav, J. S.; Singh, V. K.; Srihari, P. Org. Lett. 2014, 16, 836-839. doi:10.1021/ol403604u

24. Burkhard, J. A.; Wuitschik, G.; Rogers-Evans, M.; Müller, K.; Carreira, E. M. Angew. Chem., Int. Ed. 2010, 49, 9052-9067. doi:10.1002/anie.200907155

25. Wang, Z.; Chen, Z.; Sun, J. Angew. Chem., Int. Ed. 2013, 52, 6685-6688. doi:10.1002/anie.201300188

26. Burkhard, J.; Carreira, E. M. Org. Lett. 2008, 10, 3525-3526. doi:10.1021/ol801293f

27. Jaśkowska, J.; Kowalski, P. J. Heterocycl. Chem. 2008, 45, 1371-1375. doi:10.1002/jhet.5570450519 
28. Wolin, R.; Connolly, M.; Afonso, A.; Hey, J. A.; She, H.; Rivelli, M. A.; Willams, S. M.; West, R. E., Jr. Bioorg. Med. Chem. Lett. 1998, 8, 2157-2162. doi:10.1016/s0960-894x(98)00379-5

29. Calata, C.; Pfund, E.; Lequeux, T. J. Org. Chem. 2009, 74, 9399-9405. doi:10.1021/jo901540c

30. Fort, D. A.; Woltering, T. J.; Alker, A. M.; Bach, T. Heterocycles 2014, 88, 1079-1100. doi:10.3987/com-13-s(s)67

31. White, A. R.; Kozlowski, R. A.; Tsai, S.-C.; Vanderwal, C. D. Angew. Chem., Int. Ed. 2017, 56, 10525-10529. doi:10.1002/anie.201704119

32. Fort, D. A.; Woltering, T. J.; Nettekoven, M.; Knust, H.; Bach, T. Chem. Commun. 2013, 49, 2989-2991. doi:10.1039/c3cc40757h

\section{License and Terms}

This is an Open Access article under the terms of the Creative Commons Attribution License

(http://creativecommons.org/licenses/by/4.0). Please note that the reuse, redistribution and reproduction in particular requires that the authors and source are credited.

The license is subject to the Beilstein Journal of Organic Chemistry terms and conditions:

(https://www.beilstein-journals.org/bjoc)

The definitive version of this article is the electronic one which can be found at: doi:10.3762/bjoc. 16.160 